\title{
An interstitial deletion within 9p21.3 and extending beyond CDKN2A predisposes to melanoma, neural system tumours and possible haematological malignancies
}

\author{
Maria J Baker, ${ }_{1}^{1}$ Alisa M Goldstein, ${ }^{2}$ Patricia L Gordon, ${ }^{3}$ Kimberly S Harbaugh, ${ }^{4}$ \\ Heath B Mackley, ${ }^{5}$ Michael J Glantz, ${ }_{1}^{4}$ Joseph J Drabick ${ }^{1}$
}

${ }^{1}$ Department of Medicine, Penn State Milton S. Hershey Medical Center, Penn State Hershey Cancer Institute, Hershey, Pennsylvania, USA ${ }^{2}$ Division of Cancer Epidemiology and Genetics, Genetic Epidemiology Branch, National Cancer Institute, Bethesda, Maryland, USA ${ }^{3}$ Department of Pediatrics, Penn State Milton S. Hershey Medical Center, Penn State Hershey Cancer Institute, Hershey, Pennsylvania, USA ${ }^{4}$ Department of Neurosurgery, Penn State Milton S. Hershey Medical Center, Penn State Hershey Cancer Institute, Hershey, Pennsylvania, USA ${ }^{5}$ Department of Radiation Oncology, Penn State Milton S. Hershey Medical Center, Penn State Hershey Cancer Institute, Hershey,

Pennsylvania, USA

\section{Correspondence to}

Dr Maria J Baker, Department of Medicine, Penn State Milton S. Hershey Medical Center, Penn State Hershey Cancer Institute, 500 University Drive CH46, Hershey,

PA 17033-0850, USA;

mbaker@hmc.psu.edu

Received 6 August 2015 Revised 25 November 2015 Accepted 22 December 2015 Published Online First 21 January 2016

CrossMark

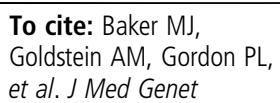

\section{ABSTRACT}

Familial atypical multiple mole melanoma syndrome (FAMMM) is characterised by dysplastic naevi, malignant melanoma and pancreatic cancer. Given that large deletions involving CDKN2A (cyclin-dependent kinase inhibitor $2 A$ ) account for only $2 \%$ of cases, we describe a family that highlights the co-occurrence of both melanoma and neural system tumours to aid clinical recognition and propose a management strategy. A patient with multiple neurofibromas was referred with a provisional diagnosis of neurofibromatosis type 1 (NF1). Prior molecular testing, though, had failed to identify an NF1 mutation by sequencing and multiplex ligationdependent probe amplification. His family history was significant for multiple in situ/malignant melanomas at young ages and several different cancers reminiscent of an underlying syndrome. A search of the Familial Cancer Database, FaCD Online, highlighted several families with cutaneous melanoma and nervous system tumours who were subsequently identified to have large deletions spanning CDKN2A. Although sequencing of CDKN2A and TP53 failed to identify a mutation, a heterozygous CDKN2A deletion was identified by targeted array comparative genomic hybridisation (CGH). Wholegenome oligonucleotide array CGH and SNP analysis identified an interstitial deletion of at least $1.5 \mathrm{Mb}$ within 9p21.3 and spanning approximately 25 genes. Identification of the underlying molecular abnormality permits predictive testing for at-risk relatives. Given the young cancer diagnoses, a surveillance regimen was developed and a clinical team organised for ongoing management so that genetic testing could be offered to both adults and minor children. Surveillance recommendations addressed cancer risks associated with FAMMM, and other cancers exhibited by this family with a large contiguous gene deletion.

\section{INTRODUCTION}

Familial atypical multiple mole melanoma syndrome (FAMMM) is an autosomal dominant cancer predisposition syndrome characterised by multiple dysplastic naevi, malignant melanoma and, in some families, a potential increased risk for pancreatic cancer. This cancer predisposition syndrome has also been referred to as dysplastic naevus syndrome and represents one of several genetic aetiologies underlying familial cutaneous malignant melanoma (FCMM)

The CDKN2A (cyclin-dependent kinase inhibitor 2A) gene, localised to chromosome $9 \mathrm{p} 21$, is the major known high-risk susceptibility gene for FAMMM/FCMM. CDKN2A codes for two distinct tumour suppressor proteins, $\mathrm{p} 16^{\mathrm{INK} 4 \mathrm{~A}}$ and $\mathrm{p} 14^{\mathrm{ARF}}$, which are transcribed using alternative first exons, $1 \alpha$ and $1 \beta$, and subsequently spliced onto the common exons 2 and 3 , but in different reading frames. $\mathrm{p} 16^{\mathrm{INK} 4 \mathrm{~A}}$ acts through the $\mathrm{pRb}$ pathway and functions normally to inhibit the kinase activity of CDK4. In contrast, $\mathrm{p} 14^{\mathrm{ARF}}$ exerts its biological effects through the p53 pathway. Ultimately, mutations in the CDKN2A gene can cause loss of function of either or both proteins, and so each may contribute to the development of different types of cancer. ${ }^{1}$

Germline CDKN2A mutations have been identified in upwards of $15 \%-40 \%$ of patients with FCMM, while an additional $1 \%-2 \%$ of familial cases are due to mutations in the CDK4 gene. ${ }^{2}{ }^{3}$ Recently, three additional high-risk susceptibility genes for familial melanoma were identified, specifically BAP1, TERT and POT1, all of which are less frequent than $C D K 4 .^{4-7}$ As such, there are likely other genes, not yet identified, that account for the remaining families with a hereditary predisposition to melanoma.

CDKN2A mutations were first reported in kindreds with familial melanoma in 1994 with missense mutations representing the predominant type of mutation identified. ${ }^{8}{ }^{9}$ Nonsense mutations, as well as small deletions and insertions, have also been reported. Large deletions, though, involving one or more exons, account for only $2 \%$ of all mutations reported in the CDKN2A gene. ${ }^{3} 10$

Of the small number of families worldwide that have been described with large deletions involving CDKN2A, some have exhibited a predisposition to both melanoma and nervous system tumours (NST), prompting several investigators to propose that this combination of tumours may represent a discrete syndrome. ${ }^{11-14}$ Several case reports have specifically described these families as demonstrating tumours characteristic of both FAMMM and neurofibromatosis type 1 (NF1). ${ }^{14-17}$ For example, the family described by Bahuau et al ${ }^{14}$ exhibited many tumours associated with NF1, including both neurofibroma and astrocytoma, as well as features characteristic of FAMMM such as multiple cutaneous malignant melanoma and dysplastic naevi. The family reported by Bahuau et al, though, also exhibited some tumours characteristic of neurofibromatosis type 2 (NF2) such as schwannomas and meningiomas. We report a family with a large, contiguous gene deletion 
involving chromosome 9p21.3, and extending beyond CDKN2A to include approximately 25 genes, with tumours characteristic of FAMMM and NF1, and several additional tumours including a primitive neuroectodermal tumour (PNET), chondrosarcoma and leukaemia. The constellation of tumours exhibited by this family necessitated the development of a tailored surveillance regimen for ongoing clinical management of both adults, as well as minor children, given the high prevalence of young cancer diagnoses across multiple generations.

\section{METHODS}

\section{Patient and family}

A 52-year-old Caucasian male with a provisional diagnosis of NF1 was referred to the Penn State Hershey Cancer Genetics Program by his oncologist for cancer genetic counselling and testing. A review of his personal history was significant for a squamous papilloma below the left eye which was diagnosed at 40 years of age, a benign fibrous histiocytoma of the lower back at 43 years of age, and one junctional naevus of the right upper arm with moderate to focal severe atypia at 44 years of age. In addition, his personal history was significant for multiple, painful neurofibromas which were diagnosed at 49 years of age, consisting of two in the retroperitoneum and one excised from the sciatic nerve. Subsequent review of his electronic medical record revealed that he had previously pursued a clinical genetics consult which included testing for NF1. The NF1 gene was analysed by long-range RT-PCR and sequencing using dyeterminator chemistry on an ABI PRISM capillary sequencer followed by multiplex ligation-dependent probe amplification (MLPA), the results of which were negative. Physical examination by a clinical geneticist documented the presence of multiple hyperpigmented naevi, but there was no evidence, besides the multiple nerve sheath tumours/neurofibromas, of other stigmata characteristic of NF1, such as Lisch nodules or café au lait spots. As such, the proband did not meet clinical diagnostic criteria for NF1.

A review of his family history was significant for multiple relatives, spanning three generations, with both in situ and malignant cutaneous melanomas. His mother was diagnosed with a malignant melanoma at 14 years of age following which she died from metastatic disease at 29 years of age. In addition, his sister was diagnosed with melanoma in situ at 47 years of age and had a history of multiple naevi with atypia. The family history was also significant for a niece with melanoma in situ at 27 years of age. This niece had four additional naevi removed, one of which demonstrated slight atypia, and she had one lipoma. Of this niece's three daughters, one had a Spitz tumour excised at 5 years of age, possibly representing a precursor lesion to melanoma, and another daughter had five lipomas. In addition, the proband's family history was significant for his son who was diagnosed with a pontomedullary PNET with leptomeningeal spread at 18 years of age, his brother with chondrosarcoma of the inguinal region at 25 years of age followed by the removal of three compound naevi at 27 years of age and his brother's son with leukaemia which was diagnosed at 11 years of age. Other relatives with a history of cancer included his maternal grandmother with a reported diagnosis of cervical cancer at approximately 35 years of age and four great aunts and uncles, all with unspecified cancers under 55 years of age (see figure 1).

\section{Genetic testing}

Given that prior analysis of the NF1 gene was negative by both sequencing and MLPA, the proband was offered testing of the
CDKN2A gene, which, at the time, consisted of sequencing only, to address the family history of multiple in situ and malignant melanomas and multiple atypical naevi. Amplified DNA products were sequenced in forward and reverse directions using fluorescent dye-labelled sequencing primers with chromatographic tracings of each amplicon analysed by a proprietary computer-based review followed by visual inspection and confirmation. In addition, he was offered both sequencing and MLPA analysis of the TP53 gene based on his family history of the PNET, chondrosarcoma and leukaemia, with mutations in this gene responsible for Li-Fraumeni syndrome. Amplified DNA was analysed by direct DNA sequence analysis on an automated fluorescent sequencer with sequencing of the entire coding region and associated splice junctions performed in both directions. MLPA products were analysed by DNA fragment analysis on an automated fluorescence sequencer with the absence or presence of deletions/duplications of one or more exons confirmed by MLPA analysis using an independently amplified segment. A search of the Familial Cancer Database, FaCD Online, revealed the identification of a small number of reported families worldwide with cutaneous malignant melanoma in the presence of NSTs, features reminiscent of both FAMMM and NF1, in the context of large deletions within and extending beyond CDKN2A that would not be detected by standard sequencing methods. ${ }^{18} 19$ As a result, the proband was also offered large rearrangement analysis of the CDKN2A gene via array-based comparative genomic hybridisation (aCGH), with the array containing multiple oligonucleotide probes in most exons and/or their flanking intronic regions, through another reference laboratory, if Sanger sequencing proved negative. Hybridisation data were analysed with the Genomic Workbench V.5 software (Agilent Technologies) to evaluate copy number at the exon level. Targeted exon-level array CGH was followed by whole-genome oligonucleotide array CGH and SNP analysis with the array design based on human genome build GRCh37/hg19.

\section{RESULTS}

Genomic DNA was isolated from the proband's peripheral blood specimen. Subsequent sequencing, though, of the CDKN2A gene, including all exons and adjacent intronic regions, failed to identify a deleterious mutation underlying his personal and family history of cancer. Genetic testing also proved negative for a possible TP53 mutation following both sequencing and MLPA analysis. Targeted array CGH of the CDKN2A gene with exon-level resolution revealed a heterozygous deletion. Although this molecular result was informative for FCMM, the extent of the deletion beyond CDKN2A could not be determined by this assay alone. Subsequent wholegenome oligonucleotide array CGH and SNP analysis identified an interstitial deletion of at least $1.5 \mathrm{Mb}$ within cytogenetic band 9p21.3 with sequence coordinates of chr9:20,951,885-22,447,709[hg19]. The deleted interval was found to include approximately 25 genes, of which only one, CDKN2A, was known to be associated with a cancer predisposition syndrome, specifically FCMM. See figure 2A, B. Additionally, the proband was identified to have two CNVs of unknown clinical significance: a duplication of at least $229 \mathrm{~kb}$ within cytogenetic band $5 \mathrm{q} 35.2$ with the duplicated interval including the TSPAN17 and EIF4E1B genes and part of the $S N C B$ and UNC5A genes. The clinical consequence of carrying three copies of the $S N C B$ gene, of which missense mutations have been described in two unrelated patients with dementia and lewy bodies, or of any of the other genes in this duplicated 


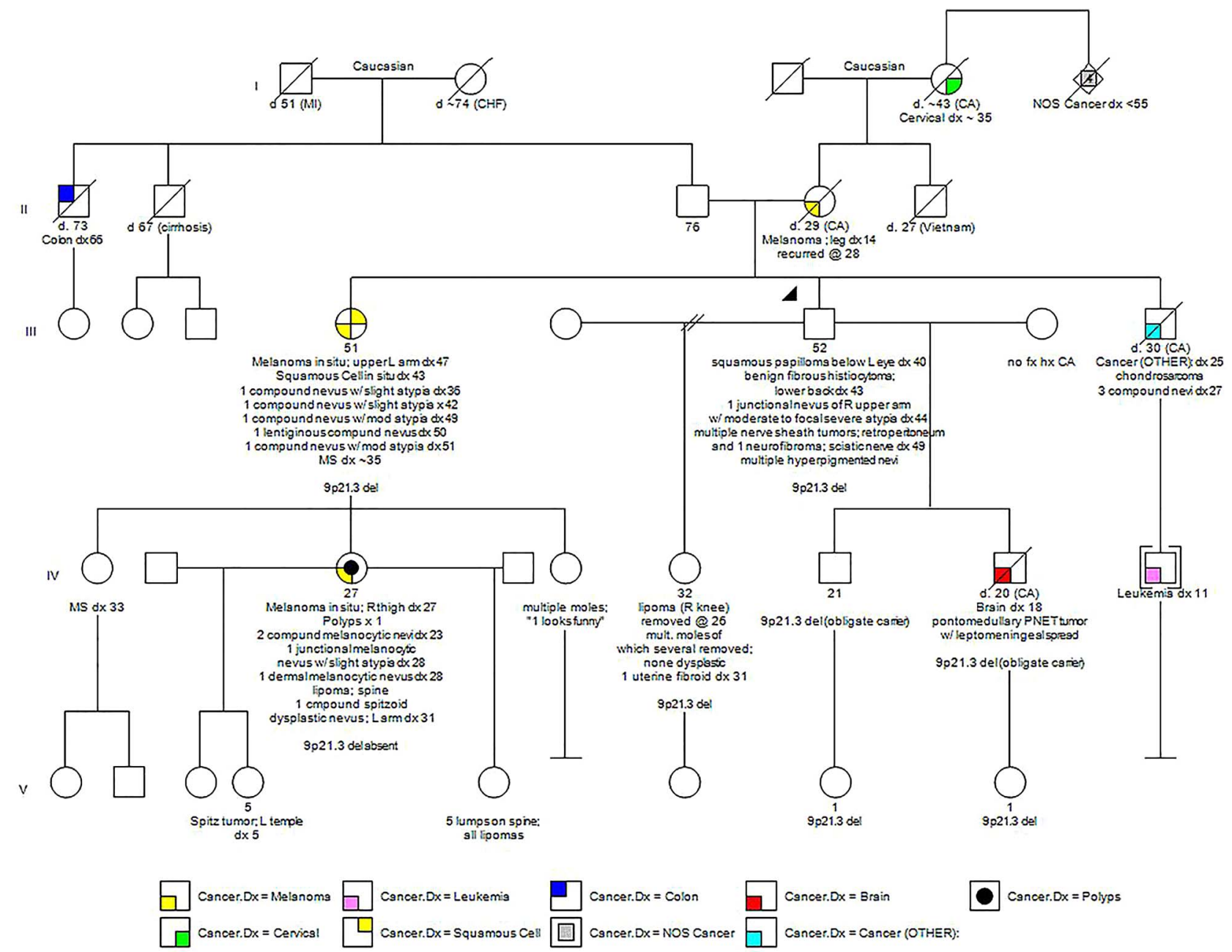

Figure 1 Family pedigree.

region has not yet been determined. ${ }^{11}$ Further, this region has not been reported to vary in copy number in the normal population. ${ }^{20}$ Lastly, the proband was found to have an amplification, consisting of four copies of at least $505 \mathrm{~kb}$, in 10q24.32-q24.33. The amplified interval included 10 genes, none of which have been associated with clinical disorders to date. ${ }^{11}$ This region in its entirety has not been reported to vary in copy number in the normal population. ${ }^{20}$ In summary, the reference laboratory reported the molecular results as arr $5 \mathrm{q} 35.2(176,052,444-176,281,813) \times 3,9 \mathrm{p} 21.3(20,951,885-22,447$, 709)x1,10q24.32q24.33(104,853,173-105,357,653)x4 sex: male.

Additional relatives tested to date include the proband's sister with multiple primary melanomas, an unaffected daughter and two unaffected granddaughters. Each of these relatives tested positive for the large interstitial deletion and, in the process, confirmed that both of the proband's sons were obligate carriers, one of whom was diagnosed with a pontomedullary PNET at 18 years of age. Most recently, the proband's niece with multiple primary melanomas tested negative for the contiguous gene deletion. This observation adds to the complexity of the family and raises the possibility that the constellation of cancers may result from multiple underlying genetic causes. Alternatively, the niece with melanoma, as well as other relatives, may be at increased risk for melanoma due to the presence of other familial risk factors.

\section{DISCUSSION}

We report a family with a large deletion of chromosome 9 p21.3, which spans approximately 25 genes and includes CDKN2A. To date, large rearrangement analysis of the $C D K N 2 A$ gene has not routinely been offered by clinical reference laboratories when $C D K N 2 A$ is ordered as a standalone test, since large deletions represent only $2 \%$ of CDKN2A mutations. ${ }^{3}{ }^{10}$ Further, the proband presented for evaluation prior to the clinical availability of multiplex panels in which multiple cancer predisposition genes are analysed by next-generation sequencing, thus routinely permitting the detection of large rearrangements. The molecular aetiology underlying this family's history of tumours was aided by the availability of an online resource called the Familial Cancer Database, which is accessible at http://www.facd.info, and was primarily developed as a tool to assist healthcare providers in developing a differential diagnosis based on the constellation of tumours and nontumour features within a family. ${ }^{18} 19$

\section{CDKN2A-associated cancer spectrum}

The identification of a large deletion encompassing CDKN2A confirmed a genetic predisposition to melanoma in the proband and a number of his at-risk relatives. In the context of FAMMM/FCMM, lifetime risk estimates for melanoma vary 
A

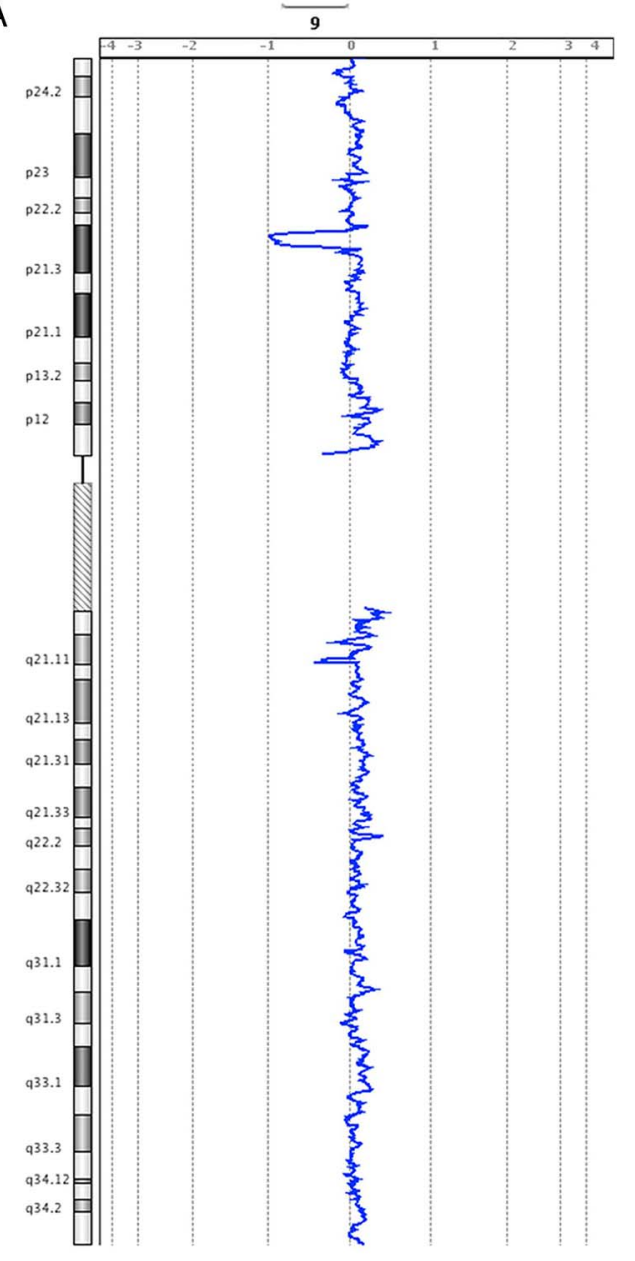

$\mathrm{B}$

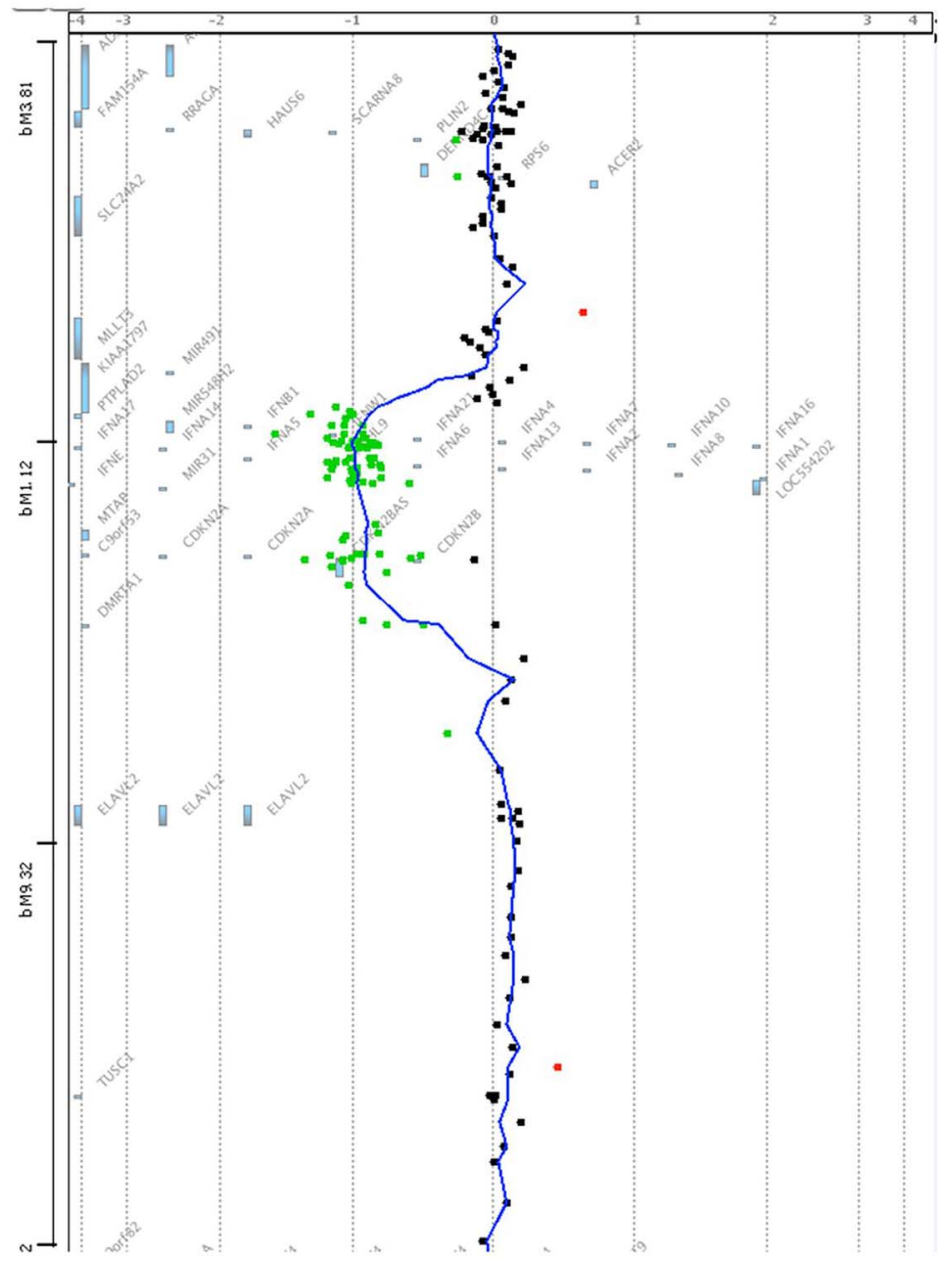

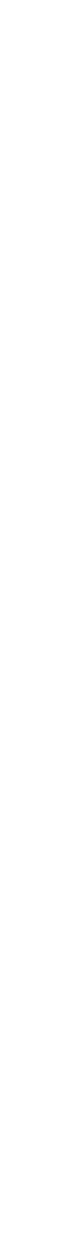

Figure 2 Array comparative genomic hybridisation (CGH) data. (A) shows the location of the deletion within cytogenetic band 9p21.3. (B) details the approximate 25 genes encompassed within the deleted region as identified in the proband. The green dots represent individual probe locations that are deleted in the proband compared with the reference DNA, based on the relative intensity of the signal. The probe locations are mapped in comparison with the genes in the genomic region. Red dots indicate probe locations whose intensity is increased in the proband relative to the reference DNA. Single probe deviations, whether red or green, represent hybridisation noise. Images provided by GeneDx.

widely, with penetrance estimates ranging from a low of $28 \%$ by 80 years of age to a high of $58 \%-92 \%$, depending on the study design. $^{21-25}$ The Melanoma Genetics Consortium, GenoMEL, also found a statistically significant effect when families lived in a geographical area with a high population incidence of melanoma. ${ }^{26}$ They concluded that the risk factors which influence the population incidence of melanoma may also mediate the penetrance of CDKN2A mutations.

Pancreatic cancer has also been associated with mutations in the CDKN2A gene with one study estimating a $17 \%$ risk to age $75 .^{27-29}$ Not all families, though, with a CDKN2A mutation demonstrate an increased risk of pancreatic cancer. Although previous studies have suggested that the development of pancreatic cancer may depend on whether the specific mutation identified impairs the function of the p14ARF protein in addition to $\mathrm{p} 16$, definitive evidence for this relationship has not yet been shown.

The melanoma-astrocytoma syndrome, first described in 1993, represents another phenotype postulated to be related to mutations in the CDKN2A gene. ${ }^{12}$ Since then, additional studies of families with melanoma have documented the co-occurrence of various neural system tumours, as seen in the proband's family, including rare solitary internal neurofibromas, as well as cutaneous neurofibromas. ${ }^{13}{ }^{30}$ Lynch et $a l^{31}$ also documented the association of sarcoma with malignant melanoma in two kindreds with a CDKN2A mutation. Again, however, it has not yet been possible to clearly determine the underlying cause(s) of these rarely co-occurring tumours.

\section{Genotype/phenotype correlations with large CDKN2A deletions}

Although large germline deletions of CDKN2A have only been described in a limited number of families worldwide, the breakpoints of the deletions described thus far and their impact on the function of the gene's two alternative transcripts, $\mathrm{p} 16^{\mathrm{INK} 4 \mathrm{~A}}$ and $\mathrm{p} 14^{\mathrm{ARF}}$, have begun to shed light on the underlying mechanism predisposing to the observed constellation of tumours, including dysplastic naevi, melanoma and neural system tumours. The first reported individual to carry a large deletion involving part of chromosome $9 \mathrm{p}$, as a result of an unbalanced chromosomal translocation, developed multiple melanomas and a plexiform neurofibroma. ${ }^{16}$ It was estimated that the deletion in this patient spanned at least $6 \mathrm{Mb}$ and involved CDKN2A, $A R F$ and $C D K N 2 B$. Several years later, Bahuau et al ${ }^{32}$ reported two families with melanoma and various neural system tumours, including astrocytoma, meningioma, schwanomma and 
neurofibroma, both of which exhibited deletions of a portion of chromosome $9 \mathrm{p}$.

Petronzelli et al proposed that $\mathrm{p} 14^{\mathrm{ARF}}$ was responsible, at least in part, for predisposition to neural system tumours and melanoma based on a family that carried a germline splicing mutation that resulted in a lack of exon 2 sequences, thus rendering both proteins defective. They subsequently concluded that the development of neurofibromas was due to the inactivation of $\mathrm{p} 16^{\mathrm{INK} 4 \mathrm{~A}}$ and $\mathrm{p} 14^{\mathrm{ARF}}$ or, alternatively, of $\mathrm{p} 14^{\mathrm{ARF}}$ alone. ${ }^{17}$ Pasmant et $a l^{33}$ detected a large germline deletion, which included the entire $p 15 / C D K N 2 B-p 16 / C D K N 2 A-p 14 / A R F$ gene cluster, in a family with cutaneous malignant melanoma and neural system tumours, suggesting a contiguous gene deletion syndrome. However, in their study, they also identified a new long non-coding RNA, within the germline deletion, which they called ANRIL (Antisense Noncoding RNA in the INK4A Locus). More recently, Vanneste et $a l^{34}$ reported a patient with multiple neurofibromas and a solitary spinal neurofibroma who was found to have a deletion of 14 nucleotides in exon 2 of CDKN2A, providing further evidence that $\mathrm{p} 14^{\mathrm{ARF}}, \mathrm{p} 16^{\mathrm{INK} 4 \mathrm{~A}}$ and/or ANRIL, now designated CDKN2B-AS1, may be specifically involved in the aetiology of neurofibromas as a feature of FAMMM. However, numerous FCMM families with large deletions impacting p14 ${ }^{\mathrm{ARF}}$ do not have neural system tumours 35 [Goldstein et al unpublished data 2015]. Thus, further study is required to understand the relationship between CMM, NST, CDKN2A, CDKN2B, CDKN2B-AS1 and other 9p21 genes. Although the contribution of ANRIL expression to neural system tumours remains unknown, SNPs which alter its expression, have been associated with numerous diseases including coronary artery disease, stroke, diabetes as well as melanoma and glioma. ${ }^{36}$ Most recently, Frigerio et $a l^{37}$ reported a patient with both astrocytoma and multiple melanomas with the largest constitutive deletion described to date involving 9p21.3 and spanning approximately $2135 \mathrm{Mb}$. Our proband, reported herein, adds to this growing list of families with large deletions extending beyond CDKN2A, thus raising the question of whether or not this could represent an emerging contiguous gene deletion syndrome.

\section{Clinical implications}

Based on the identification of a molecular deletion encompassing $C D K N 2 A$, the proband and his at-risk family members were instructed to follow FAMMM/FCMM surveillance recommendations which typically include total body skin examinations every 6-12 months by a dermatologist, beginning at 10 years of age and including whole body photography. ${ }^{24} 38$ Given the early-onset skin lesions within the family, though, baseline dermatological examinations were recommended to begin during the first few years of life. Most recently, the proband's niece with a history of multiple primary melanomas was identified not to carry the large deletion. Given that relatives who test negative for the known CDKN2A mutation remain at increased risk for melanoma due to other familial shared risk factors, though, they should pursue heightened skin surveillance, regardless of their genetic status. ${ }^{39}{ }^{40}$ Lastly, with regard to dermatological recommendations, family members were educated regarding proper sun protection measures. Current FAMMM/ FCMM surveillance recommendations also address the potential increased risk for pancreatic cancer in mutation positive family members. As such, the patient and his at-risk family members were instructed to discuss the role of endoscopic ultrasound of the pancreas, as well as possible measurement of the CA-19-9 tumour marker with a gastroenterologist.
Developing a tailored management strategy for this family, which addressed other cancer risks potentially associated with the large deletion, was limited by the fact that several relatives were unavailable for study. As a result, it was not possible to determine whether the brother and the nephew with respective diagnoses of chondrosarcoma and leukaemia each carried the large familial deletion. In contrast, the proband's son with the PNET, although unavailable for study, was determined to be an obligate carrier, given that his daughter tested positive for the familial deletion. As such, the following medical management recommendations were developed based on the family's specific history of benign tumours/cancers: (1) annual comprehensive physical examination, including a careful neurological examination, (2) consideration of whole-body MRI, (3) abdominal ultrasound and brain MRI on an annual basis and (4) bloodwork every 4 months to include complete blood count, erythrocyte sedimentation rate and lactate dehydrogenase. Given the proband's son who was diagnosed with a PNET at 18 years of age, baseline brain MRI was recommended beginning at 8 years of age. In addition, annual dilated ophthalmology evaluation by an ophthalmologist was recommended to look for optic glioma or papilledema, a sign of increased intracranial pressure which can occur secondary to the presence of a brain tumour. In summary, the medical team acknowledged that the proposed surveillance regimen was quite intensive. Given the proband's son, though, who, at the time, was actively dying from leptomeningeal spread of his PNET and the rather young diagnoses of melanoma within the family, this regimen was developed as a starting point for discussion with the clinical geneticist who ultimately would be responsible for overseeing the family's ongoing medical management. Lastly, although our proband did not meet clinical diagnostic criteria for NF1, nor did genetic testing confirm a molecular diagnosis, there could, likewise, be a potential risk to develop malignant peripheral nerve sheath tumours within the field of radiation treatment. As such, it was recommended that any decisions regarding radiation therapy be made in the context of a discussion with a radiation oncologist regarding the risks, benefits, and limitations of such treatment. $^{4142}$

Beyond the challenge of developing a management strategy for the proband and his at-risk relatives, given the paucity of families worldwide with a similar contiguous gene deletion, there was the ethical dilemma of whether presymptomatic testing should be offered to minor children. Typically, the appropriateness of offering presymptomatic testing to minors depends on the specific cancer predisposition syndrome segregating within the family and whether it is known to predispose to childhood cancers, and the phenotypic variability observed within the family. Given the early-onset cancers exhibited by family members and the development of an intensive management strategy, a number of the proband's relatives, both affected and unaffected, have since requested testing for both themselves and their minor children. To date, five additional relatives, ranging in age from 1 to 52 years of age, have now pursued testing and all but one was confirmed to carry the familial deletion.

Lastly, the proband's large deletion within 9p21.3 contains a number of candidate genes which make up the interferon gene cluster and have been shown to be important for patient survival and success of interferon therapy, beyond containing genes important in melanoma susceptibility. ${ }^{43}$ Linsley et al, ${ }^{44}$ for example, linked loss of this locus with reduced immune cell genes within melanoma tumours. They concluded that loss of 9 p21.3 may lead or contribute to reduced immune surveillance 
and/or tumour destruction by the immune system. Thus, the family members described here, who develop melanoma in the context of the large deletion containing the interferon gene cluster, as well as others similarly affected with loss of $9 \mathrm{p} 21.3$, may be more likely to suffer metastatic disease and hence a worse prognosis. Chromosomal instability was recently demonstrated to be a mechanism for modulating local cytokine expression in colorectal tumours. ${ }^{45}$ Thus, emerging evidence suggests that genomic rearrangements within tumours may represent a broader mechanism for modulating antitumour immunity and, as such, could potentially influence the choice of treatment regimen in a family, such as the one presented here with a large deletion within 9p21.3, if and when tumours develop. ${ }^{44}$

\section{Limitations}

Our understanding regarding the spectrum of cancers associated with this family's contiguous gene deletion is limited by the paucity of families described in the literature with similar deletions. Further, within this family, it has yet to be determined whether the respective diagnoses of chondrosarcoma and leukaemia of brother and nephew occurred in conjunction with the familial deletion, whether there is more than one condition segregating within this family, or whether these diagnoses represent sporadic cancers within a family that has a genetic predisposition. For example, some of the features exhibited by the proband and/or his relatives are described in patients with PTEN hamartoma tumour syndrome (PHTS) such as the lipomas, the papilloma and the increased risk for melanoma. A next-generation sequencing panel, including PTEN, and potentially other cancer susceptibility genes, could address the possibility of an additional cancer syndrome segregating within the family. In addition, the specific contribution of the other genes within the contiguous deletion, if any, on the phenotype has not been explored. Lastly, although subsequent testing of the proband's sister identified that she shared both CNVs of unknown significance in common with her brother, in addition to the large deletion of chromosome $9 \mathrm{p} 21.3$, it has yet to be determined from which side(s) of the family the CNVs originated.

\section{CONCLUSION}

The family described here has a rare contiguous gene deletion which includes $C D K N 2 A$, and predisposes to multiple melanoma/dysplastic naevi characteristic of FAMMM/FCMM. The constellation of additional tumours within this family raises the question as to whether there is another cancer syndrome cosegregating within the family. The identification of the contiguous gene deletion underlying this family's hereditary predisposition to cancer was aided by the Familial Cancer Database which is a useful online tool to assist clinicians in the development of a differential diagnosis based on a family's specific history of various benign and malignant tumours. Based on our experience with this family and our review of similar cases within the literature, large rearrangement analysis of the CDKN2A gene should be considered if traditional Sanger sequencing of CDKN2A proves negative, when there is a family history of multiple melanoma concerning for FAMMM/FCMM, in the context of neural system tumours. Likewise, clinicians should consider both sequencing and large rearrangement analysis of the CDKN2A gene in patients, with neural system tumours suspicious, but not diagnostic for NF1 whose testing proves negative when there is a personal or family history of melanoma. Improved identification of these families will be further augmented by the increasing usage of next-generation sequencing pan cancer panels, which include $C D K N 2 A$, as well as whole- genome sequencing, both of which routinely detect large deletions and duplications, thus permitting better characterisation of the phenotype associated with this family's contiguous gene deletion. Lastly, predictive testing of minor children may be warranted in families with large deletions spanning CDKN2A, given the young cancer diagnoses observed in this family and assuming a clinical team can be assembled to develop a surveillance regimen that has the potential to impact prognosis of affected relatives. Further study of additional families with similar deletions spanning CDKN2A and beyond are needed to help guide genetic counselling and anticipatory care for these patients and to better understand this potentially evolving cancer predisposition syndrome.

Acknowledgements The authors thank Kathleen Hruska, PhD, FACMG with GeneDx of Gaithersburg, MD for providing images illustrating the extent of the deleted region in the proband.

Contributors Genetic counselling and coordination of genetic testing: MJB. Ongoing medical management: PLG, KSH, HM, MJG and JJD. Drafting and critical revision of the manuscript: MJB, AMG, PLG, KSH, HM, MJG and JJD. All authors read and approved the final manuscript. KSH provided images of array CGH data.

Funding This work was supported in part by the Intramural Research Program of the US National Institutes of Health $(\mathrm{NIH})$, National Cancer Institute (NCI), Division of Cancer Epidemiology and Genetics (DCEG).

Competing interests None declared.

Patient consent Obtained.

Provenance and peer review Not commissioned; externally peer reviewed.

\section{REFERENCES}

1 Ghiorzo P, Gargiulo S, Pastorino L, Nasti S, Cusano R, Bruno W, Gliori S, Sertoli MR, Burroni A, Savarino V, Gensini F, Sestini R, Queirolo P, Goldstein AM, Bianch Scarrà G. Impact of E27X, a novel CDKN2A germ line mutation, on p16 and p14ARF expression in Italian melanoma families displaying pancreatic cancer and neuroblastoma. Hum Mol Genet 2006;15:2682-9. http://dx.doi.org/10.1093/hmg/ dd199

2 Hayward NK. Genetics of melanoma predisposition. Oncogene 2003;22:3053-62.

3 Goldstein AM, Chan M, Harland M, Gillanders EM, Hayward NK, Avril M-F, Azizi E, Bianchi-Scarra G, Bishop DT, Bressac-de Paillerets B, Bruno W, Calista D, Cannon Albright LA, Demenais F, Elder DE, Ghiorzo P, Gruis NA, Hansson J, Hogg D, Holland EA, Kanetsky PA, Kefford RF, Landi MT, Lang J, Leachman SA, MacKie RM, Magnusson V, Mann GJ, Niendorf K, Bishop JN, Palmer JM, Puig S, Puig-Butille JA de Snoo FA, Stark M, Tsao H, Tucker MA, Whitaker L, Yakobson E, The Lund Melanoma Study Group, and the Melanoma Genetics Consortium (GenoMEL) High-risk melanoma susceptibility genes and pancreatic cancer, neural system tumors, and uveal melanoma across GenoMEL. Cancer Res 2006;66:9818-28.

4 Wiesner T, Obenauf AC, Murali R, Fried I, Griewank KG, Ulz P, Windpassinger C, Wackernagel W, Loy $S$, Wolf I, Viale A, Lash AE, Pirun $M$, Socci ND, Rütten A, Palmedo G, Abramson D, Offit K, Ott A, Becker JC, Cerroni L, Kutzner H, Bastian $B C$, Speicher MR. Germline mutations in BAP1 predispose to melanocytic tumors. Nat Genet 2011;43:1018-21.

5 Horn S, Figl A, Rachakonda PS, Fischer C, Sucker A, Gast A, Kadel S, Moll I, Nagore E, Hemminki K, Schadendorf D, Kumar R. TERT promoter mutations in familial and sporadic melanoma. Science 2013;339:959-61.

6 Robles-Espinoza CD, Harland M, Ramsay AJ, Aoude LG, Quesada V, Ding Z, Pooley $K A$, Pritchard AL, Tiffen JC, Petljak M, Palmer JM, Symmons J, Johansson P, Stark MS, Gartside MG, Snowden H, Montgomery GW, Martin NG, Liu JZ, Choi J, Makowski M, Brown KM, Dunning AM, Keane TM, López-Otín C, Gruis NA, Hayward NK, Bishop DT, Newton-Bishop JA, Adams DJ. POT1 loss-of-function variants predispose to familial melanoma. Nat Genet 2014;46:478-81.

7 Shi J, Yang XR, Ballew B, Rotunno M, Calista D, Fargnoli MC, Ghiorzo P, Bressac-de Paillerets B, Nagore E, Avril MF, Caporaso NE, McMaster ML, Cullen M, Wang Z, Zhang $X_{;}$NCI DCEG Cancer Sequencing Working Group; NCI DCEG Cancer Genomics Research Laboratory; French Familial Melanoma Study Group, Bruno W, Pastorino L, Queirolo P, Banuls-Roca J, Garcia-Casado Z, Vaysse A, Mohamdi H, Riazalhosseini Y, Foglio M, Jouenne F, Hua X, Hyland PL, Yin J, Vallabhaneni $H$, Chai W, Minghetti P, Pellegrini C, Ravichandran S, Eggermont A, Lathrop M, Peris K, Scarra GB, Landi G, Savage SA, Sampson JN, He J, Yeager M, Goldin LR, Demenais F, Chanock SJ, Tucker MA, Goldstein AM, Liu Y, Landi MT. Rare missense variants in POT1 predispose to familial cutaneous malignant melanoma. Nat Genet 2014;46:482-6.

8 Kamb A, Shattuck-Eidens D, Eeles R, Liu Q, Gruis NA, Ding W, Hussey C, Tran T, Miki Y, Weaver-Feldhaus J, McClure M, Aitken JF, Anderson DE, Bergman W, Frants 
R, Goldgar DE, Green A, MacLennan R, Martin NG, Meyer LJ, Youl P, Zone JJ, Skolnick MH, Cannon-Albright LA. Analysis of the p16 gene (CDKN2) as a candidate for the chromosome $9 p$ melanoma susceptibility locus. Nat Genet 1994;8:22-6.

9 Hussussian CJ, Struewing JP, Goldstein AM, Higgins PAT, Ally DS, Sheahan MD, Clark WHJr, Tucker MA, Dracopoli NC. Germline p16 mutations in familial melanoma. Nat Genet 1994;8:15-21.

10 Mistry SH, Taylor C, Randerson-Moor JA, Harland M, Turner F, Barrett JH, Whitaker L, Jenkins RB, Knowles MA, Newton Bishop JA, Bishop DT. Prevalence of 9p21 deletions in UK melanoma families. Genes Chromosomes Cancer 2005:44:292-300.

11 Online Mendelian Inheritance in Man (OMIM). http://omim.org/entry/155755 (accessed 29 Jul 2015).

12 Kaufman DK, Kimmel DW, Parisi JE, Michels VV. A familial syndrome with cutaneous malignant melanoma and cerebral astrocytoma. Neurology 1993:43:1728-31.

13 Azizi E, Friedman J, Pavlotsky F, Iscovich J, Bornstein A, Shafir R, Trau H, Brenner H and Nass D. Familial cutaneous malignant melanoma and tumors of the nervous system. Cancer 1995;76:1571-8.

14 Bahuau M, Vidaud D, Kujas M, Palangie A, Assouline B, Chaignaud-Lebreton M, Prieur M, Vidaud M, Harpey J-P, Lafourcade J, Caille B. Familial aggregation of malignant melanoma/dysplastic naevi and tumors of the nervous system: an original syndrome of tumour proneness. Ann Genet 1997;40:78-91.

15 Stokkel MPM, Kroon BBR, van der Sande JJ, Neering H. Malignant cutaneous melanoma associated with neurofibromatosis in two sisters from a family with familial atypical multiple mole melanoma syndrome. Case reports and review of the literature. Cancer 1993;72:2370-5.

16 Petty EM, Gibson LH, Fountain JW, Bolognia JL, Yanng-Feng TL, Housman DE, Bale AE. Molecular definition of a chromosome 9p21 germ-line deletion in a woman with multiple melanomas and a plexiform neurofibroma: implications for $9 p$ tumor-suppressor gene(s). Am J Hum Genet 1993;53:96-104.

17 Petronzelli F, Sollima D, Coppola G, Martini-Neri ME, Neri G, Genuardi M. CDKN2A germline splicing mutation affecting both $p 16^{\mathrm{INK} 4}$ and $p 14^{\mathrm{ARF}}$ RNA processing in a melanoma/neurofibroma kindred. Genes Chromosomes Cancer 2001;31:398-401.

18 Sijmons RH, Burger GTN. Familial cancer database: a clinical aide-mémoire. Fam Cancer 2001;1:51-5.

19 Sijmons RH, Burger GTN, Rolf $\mathrm{H}$. The use of a diagnostic database in clinical oncogenetics. Hered Cancer Clin Pract 2003;1:31-3.

20 Database of Genomic Variants. http://projects.tcag.ca/variation

21 Begg CB, Orlow I, Hummer AJ, Armstrong BK, Kricker A, Marrett LD, Millikan RC, Gruber SB, Anton-Culver H, Zanetti R, Gallagher RP, Dwyer T, Rebbeck TR, Mitra N Busam K, From L, Berwick M, for the Genes Environment and Melanoma (GEM) Study Group. Lifetime risk of melanoma in CDKN2A mutation carriers in a population-based sample. J Natl Cancer Inst 2005;97:1507-15.

22 Cannon-Albright LA, Goldgar DE, Meyer LJ, Lewis CM, Anderson DE, Fountain JW, Hegi ME, Wiseman RW, Petty EM, Bale AE, Olopade OI, Diaz MO, Kwiatkowski DJ Piepkorn MW, Zone JJ, Skolnick MH. Assignment of a locus for familial melanoma, MLM, to chromosome 9p13-p22. Science 1992:258:1148-52.

23 Parker JF, Florell SR, Alexander A, DiSario JA, Shami PJ, Leachman SA. Pancreatic carcinoma surveillance in patients with familial melanoma. Arch Dermatol 2003;139:1019-25.

24 Czajkowski R, Placek W, Drewa G, Czajkowska A, Uchańska G. FAMMM syndrome: pathogenesis and management. Dermatol Surg 2004;30Pt 2):291-6.

25 Cust AE, Armstrong BK, Goumas C, Jenkins MA, Schmid H, Hopper JL, Kefford RF, Giles GG, Aitken JF, Mann GJ. Sunbed use during adolescence and early adulthood is associated with increased risk of early-onset melanoma. Int I Cancer 2011:128:2425-35.

26 Bishop DT, Demenais F, Goldstein AM, Bergman W, Newton Bishop J, Bressac-de Paillerets B, Chompret A, Ghiorzo P, Gruis N, Hansson J, Harland M, Hayward N, Holland EA, Mann GJ, Mantelli M, Nancarrow D, Platz A, Tucker MA. Geographica variation in the penetrance of CDKN2A mutations for melanoma. J Natl Cancer Inst 2002;94:894-903.

27 Goldstein AM, Fraser MC, Struewing JP, Hussussian CJ, Ranade K, Zametkin DP, Fontaine LS, Organic SM, Dracopoli NC, Clark WH, Jr, Tucker MA. Increased risk of pancreatic cancer in melanoma-prone kindreds with p16 (INK4) mutations. N Engl J Med 1995:333:970-4

28 Whelan AJ, Bartsch D, Goodfellow PJ. A familial syndrome of pancreatic cancer and melanoma with a mutation in the CDKN2A tumor-suppressor gene. $N$ Engl I Med 1995;333:975-7.

29 Vasen HF, Gruis NA, Frants RR, van Der Velden PA, Hille ET, Bergman W. Risk of developing pancreatic cancer in families with familial atypical multiple mole melanoma associated with a specific 19 deletion of p16 (p16-Leiden). Int J Cancer 2000;87:809-11

30 Randerson-Moor JA, Harland M, Williams S, Cuthbert-Heavens D, Sheridan $E_{\text {, }}$ Aveyard J, Sibley K, Whitaker L, Knowles M, Bishop JN, Bishop DT. A germline deletion of p14(ARF) but not CDKN2A in a melanoma-neural system tumour syndrome family. Hum Mol Genet 2001;10:55-62.

31 Lynch HT, Deters CA, Hogg D, Lynch JF, Kinarsky Y, Gatalica Z. Familial sarcoma: challenging pedigrees. Cancer 2003:98:1947-57.

32 Bahuau M, Vidaud D, Jenkins RB, Bieche I, Kimmel DW, Assouline B, Smith JS, Alderete B, Cayuela J-M, Harpey J-P, Caille B, Vidaud M. Germ-line deletion involving the INK4 locus in familial proneness to melanoma and nervous system tumors. Cancer Res 1998:58:2298-303.

33 Pasmant E, Laurendeau I, Heron D, Vidaud M, Vidaud D, Bieche I. Characterization of a germ-line deletion, including the entire INK4/ARF locus, in a melanoma-neural system tumor family: Identification of ANRIL, an antisense noncoding RNA whose expression coclusters with ARF. Cancer Res 2007;67:3963-9.

34 Vanneste R, Smith E, Graham G. Multiple neurofibromas as the presenting feature of Familial Atypical Multiple Malignant Melanoma (FAMMM) syndrome. Am J Med Genet A 2013:161:1425-31.

35 Auroy S, Avril MF, Chompret A, Pham D, Goldstein AM, Bianchi-Scarrà G, Frebourg T, Joly P, Spatz A, Rubino C, Demenais F, Bressac-de Paillerets B, French Hereditary Melanoma Study Group. Sporadic multiple primary melanoma cases: CDKN2A germline mutations with a founder effect. Genes Chromosomes Cancer 2001;32:195-202.

36 Cunnington MS, Santibanez Koref M, Mayosi BM, Burn J, Keavney B. Chromosome 9p21 SNPs associated with multiple disease phenotypes correlate with ANRIL expression. PLoS Genet 2010;6:e1000899.

37 Frigerio S, Disciglio V, Manoukian S, Peissel B, Della Torre G, Maurichi A, Collini P, Pasini B, Gotti G, Ferrari A, Rivoltini L, Massimino M, Rodolfo M. A large de novo 9p21.3 deletion in a girl affected by astrocytoma and multiple melanoma. BMC Med Genet 2014;15:59.

38 Eckerle Mize D, Bishop M, Resse E, Sluzevich J. Familial atypical multiple mole melanoma syndrome. In: Riegert-Johnson DL, Boardman LA, Hefferon T, et al. eds. Cancer syndromes. Bethesda, MD: National Center for Biotechnology Information (US), 2009. http://www.ncbi.nlm.nih.gov/books/NBK7030/

39 Kefford RF, Newton Bishop JA, Bergman W, Tucker MA. Counseling and DNA testing for individuals perceived to be genetically predisposed to melanoma: a consensus statement of the Melanoma Genetics Consortium. J Clin Oncol 1999; 17:3245-51.

40 Hansson J. Familial melanoma. Surg Clin North Am 2008;88:897-916, viii.

41 Evans D, Baser M, McGaughran J, Sharif S, Howard E, and Moran A. Malignant peripheral nerve sheath tumours in neurofibromatosis 1. J Med Genet 2002:39:311-14. Correction in J Med Genet 2003:40:304.

42 Sharif S, Ferner R, Birch JM, Gillespie JE, Gattamaneni HR, Baser ME, Evans DG. Second primary tumors in neurofibromatosis 1 patients treated for optic glioma: substantial risks after radiotherapy. I Clin Oncol 2006;24:2570-5.

43 Lenci RE, Bevier M, Brandt A, Bermejo JL, Sucker A, Moll I, Planelles D, Requena C, Nagore E, Hemminki K, Schadendorf D, Kumar R. Influence of genetic variants in type I interferon genes on melanoma survival and therapy. PLOS ONE 2012;7:e50692.

44 Linsley PS, Speake C, Whalen E, Chaussabel D. Copy number loss of the interferon gene cluster in melanomas is linked to reduced T cell infiltrate and poor patient prognosis. PLOS ONE 2014:9:e109760.

45 Mlecnik B, Bindea G, Angell HK, Sasso MS, Obenauf AC, Fredriksen T, Lafontaine L, Bilocq AM, Kirilovsky A, Tosolini M, Waldner M, Berger A, Fridman WH, Rafii A, Valge-Archer V, Pages F, Speicher MR, Galon J. Functional network pipeline reveals genetic determinants associated with in situ lymphocyte proliferation and survival of cancer patients. Sci Trans/ Med 2014;6:ra37. 